\title{
XAVIER, Antonio Carlos; CORTEZ, Suzana (Orgs.). Conversas com lingüistas. São Paulo, Parábola, 2003. $200 p$.
}

\section{Resenhado por: Adail Ubirajara Sobral}

As virtudes e controvérsias da lingüística, subtítulo de Conversas com lingüistas, saíram finalmente dos muros acadêmicos. O livro apresenta entrevistas feitas pelos organizadores com alguns dos principais estudiosos da linguagem do país, todos com mais de 20 anos de experiência acadêmica. Essa primeira amostra traz de estudiosos da semântica formal a analistas de discurso, de profissionais que se ocupam dos aspectos cognitivos a teóricos do texto, de semioticistas greimasianos a chomskyanos, de lingüistas da paz a estudiosos bakhtinianos, de estudiosos da fonética a pesquisadores da área da pragmática, de estudiosos dos usos do português a praticantes da análise da conversação, entre outros. A primeira contribuição do livro reside em mostrar, como o pretendiam os autores, a diversidade e a maturidade da reflexão e da prática dos estudos da linguagem no Brasil.

Não faltam às respostas questionamentos acerca da própria adequação das designações "lingüista" e "lingüística", bem como a idéia, louvável em todos os aspectos, de que definir esse campo de estudos depende do ponto de vista que se assume para fazê-lo. Devem-se mencionar ainda as excelentes discussões acerca do que é "servir para alguma coisa" quando se trata de ciência, e as interessantes reações sobre as relações da lingüística com a pós-modernidade, essa expressão-valise tão em voga em nossos dias. Precede cada depoimento um mini-currículo de cada entrevistado.

As perguntas feitas abarcam um largo espectro de questões relevantes para a compreensão do empreendimento do estudo lingüístico. São elas: "Que é língua? Qual à relação entre língua, linguagem å sociedade? Há vínculos necessários entre língua, pensamento à cultura? À linguagem tem sujeito? Que é lingüística? À lingüística é ciência? Para que serve à lingüística? À lingüística teria algum compromisso necessário com a educação? Como à lingüística se insere na pós-modernidade? Quais os desafios para à lingüística no século XXI?" As respostas oferecem um quadro amplo e profundo que vai por certo servir para balizar os estudos lingüísticos e dar início a um amplo diálogo intradisciplinar e

Adail Ubirajara Sobral é doutorando-LAEL/PUC-SP. 
interdisciplinar que vários entrevistados apontaram como desafio para à lingüística no século XXI. Algumas dessas perguntas, como o indicam vários entrevistados, acabam por se sobrepor, algo que, em vez de prejudicar a compreensão, a reforçou, ao levar os entrevistados a retomar numas respostas elementos de outras, o que favoreceu a emergência de uma visão de conjunto em vez de levar à fragmentação.

Além disso, e é muito interessante acompanhar os vários depoimentos desse ponto de vista, há inúmeros momentos em que os entrevistados analisam os próprios termos em que são elaboradas as perguntas. Ou seja, os depoimentos assumem em muitos momentos feições de análise lingüístico-discursiva. Algumas análises incidem sobre certos termos, como "necessário", por exemplo, que modifica a direção de algumas perguntas; outras incidem sobre a definição de termos, como é o caso de "serve" em "Para que serve à lingüística?" e de "pós-modernidade". Há momentos de grandeza, como quando alguns entrevistados confessam julgar difícil definir, por exemplo, "língua" e "lingüística". Mais do que revelar a complexidade do objeto ou da ciência, isso mostra conhecimento profundo, um saber que leva a questionar as próprias bases da atividade a que se dedicam,

Os 18 entrevistados, que trabalham em diversos estados brasileiros (com grande concentração em São Paulo), são apresentados em ordem alfabética de sobrenomes. São eles: Maria Bernadete İ . Abaurre (São Paulo); Eleonora Ñ . Albano (São Paulo); José Borges Neto (Paraná); Ataliba de Castilho (São Paulo); Carlos Alberto Faraco (Paraná); José Luiz Fiorin (São Paulo); João Wanderley Geraldi (São Paulo); Francisco C. Gomes de Matos (Pernambuco); Rodolfo llari (São Paulo); Mary Kato (São Paulo); Ingedore G. Villaça Koch (São Paulo); Luiz Antonio Marcuschi (Pernambuco); Maria Cecília Mollica (Rio de Janeiro); Diana Luz Đ. de Barros (São Paulo); Sírio Possenti (São Paulo); Kanavilill Rajagopalan (São Paulo); Margarida Salomão (Minas Gerais) e Carlos Vogt (São Paulo), este último igualmente autor do Prefácio.

A pergunta sobre o que é língua fez grande parte dos entrevistados remeter à distinção entre língua e linguagem, em alguns casos mantida e em outros contestada, trazendo relevantes informações acerca das concepções que circulam no meio acadêmico especializado. A língua é definida das mais diversas maneiras. São arroladas aqui, resumidamente, essas várias definições, que se acham detalhadas no livro, porque a leitura do livro revela que elas nortearam a reflexão acerca dos outros temas propostos. As respostas são, seguindo a ordem de apresentação: atividade, trabalho; gesto que é parte integrante de muitas outras atividades humanas; abreviação para designar os idioletos, que, esses sim, seriam objetos 
empíricos; um fenômeno multissistêmico gerido por um dispositivo sociocognitivo; complexidade estruturada, estruturante e estruturável; condensação de um homem historicamente situado; instrumento e produto do trabalho; sistema de comunicação intra/interpessoal e intra/intercultural; um tipo de competência que nós temos; um fenômeno a um só tempo biológico e produzido num contexto; simultaneamente um sistema e uma prática social; domínio público de construção simbólica e interativa do mundo; sistema organizado de relações entre processamento verbal e significado necessariamente presente em ações sociointeracionais; um fenômeno desdobrado nos domínios língua e fala, entendidos como integrados em vez de dicotômicos; ao mesmo tempo sistema formal e objeto de inscrição social e subjetiva; algo que a gente cria e molda à medida que se vai falando, um abstrato a posteriori; produção da capacidade da linguagem, uma produção histórica socialmente demarcada que envolve herança histórica, herança biológica e história pessoal, não só como condição, mas como demarcação da expressão; um fenômeno social por excelência que envolve um aspecto estrutural e as condições político-sociais e econômicas da constituição de um fenômeno de comunicação como língua.

O que une essas várias definições, em meio à aparente diversidade, é o reconhecimento da complexidade do objeto da lingüística. Nenhuma das definições deixa de levar em conta, ainda que os desenvolvimentos variem, aspectos formais e não formais, domínios da repetibilidade e da irrepetibilidade, elementos sociais e pessoais, cognitivos e interacionais, biológicos e políticos, etc. Vê-se que a lingüística é, como disse um dos entrevistados, essencialmente pós-moderna, se por isso se entender que o campo se desenvolve num ambiente de indefinição e fluidez com relação ao seu próprio objeto. Ainda que alguns tenham defendido a lingüística como ciência de uma maneira que a aproxima da concepção clássica e mesmo positivista de ciência, outros como ciência num sentido não clássico e outros ainda como uma reflexão que não tem porque impor a si um estatuto de cientificidade do tipo que por muito tempo foi dominante na epistemologia tradicional, todos reconhecem ter ela hoje objetos delimitados, mesmo que não definidos no sentido formal tradicional; metodologias reconhecíveis e reproduzíveis e outras características que tornam a lingüística uma espécie de estudo a um só tempo experimental e hermenêutico, descritivo e interpretativo, sem pretensões de explicar os fenômenos no sentido estrito de "explicar".

Se há questionamentos acerca do próprio estatuto de cientificidade das ciências consideradas paradigmáticas, como a física, sente-se a falta de uma descrição que diferencie a lingüística das ciências não-humanas naquilo que ela compartilha com as outras ciências humanas: o fato de não 
envolver sujeitos que estudam e objetos de estudo, mas sujeitos que estudam e sujeitos estudados. Falta também um questionamento mais aprofundado dos pilares da epistemologia tradicional, o sujeito desprendido cartesiano, o sujeito idealmente pronto, ser livre e racional, bem como a idéia, decorrente dessa concepção de sujeito, da sociedade como agregado de sujeitos atomizados, em vez de constituída pelas interações entre esses sujeitos, que ao mesmo tempo nela encontram as bases de sua subjetivação/socialização, sendo portanto mediadores de sua constituição simbólica.

Não que esses aspectos não tenham sido abordados direta ou indiretamente por vários entrevistados quando de suas respostas, por exemplo, à questão da existência de um sujeito da linguagem (ou da língua, como sugeriram alguns), nem que não tenha havido reflexões que envolvessem de passagem a questão da epistemologia; a falta em questão é da aplicação mais rigorosa desses elementos ao problema da cientificidade dos estudos da linguagem, e da própria definição do objeto de estudo, o que parece indicar que, embora os lingüistas comecem a questionar o modelo epistemológico de cientificidade vindo das ciências ditas exatas, seu campo ao que parece ainda não foi atingido pelas intensas discussões travadas em outros campos do conhecimento quanto à validade de uma concepção de cientificidade positivista que concebe o pesquisador como alguém capaz de transcender sua própria condição e de vê-la a partir de um ciberespaço científico, de uma virtualidade a-histórica e a-social, um sujeito interpelado como ser autônomo por imperativos de objetividade que não têm nenhuma relação com seu mundo vivido e que, em conseqüência, pode eximir-se de responsabilidade.

Não se trata de propor a substituição do absolutismo que impõe uma verdade como $a$ verdade pelo relativismo que permite aceitar tudo e que por isso é inapreensível. A atitude ética envolvida nessa reformulação de princípios epistemológicos requer a consideração da posição, do caráter situado do pesquisador, em vez de a aceitação acrítica de princípios que se impõem a partir de fora e de modo abstrato a um estudioso transcendental e sem interesses específicos. Não se trata também de negar a existência de certos universais referentes aos seres humanos nem de propor que tudo é da ordem da diferença.Trata-se de administrar a situação caótica configurada pela condição do pesquisador humano de fenômenos constitutivos de outros seres humanos, em vez de estudioso de objetos inertes.

A física, como bem lembra Carlos Vogt, já demonstrou que o observador interfere no fenômeno observado; a bioética levou ao reconhecimento de que a própria genética se altera em função do ambiente, $o$ que foi comprovado por estudos experimentais da chamada "estampagem 
genética" (genétic imprinting). Isso torna insustentável a aceitação da objetividade cientifica. A existência de parâmetros de controle dos estudos lingüísticos, apontada por alguns entrevistados, não garante sua objetividade, dado que esses parâmetros são administrados por seres humanos; assim, é vital desenvolver formas de incorporar legitimamente o subjetivo às pesquisas sem por isso destruir o compromisso com o respeito às descobertas feitas, ao caráter dos dados a partir dos quais se constrói o objeto. Mas já se começa a caminhar nessa direção, a julgar por algumas passagens de vários depoimentos.

No tocante ao sujeito da língua/linguagem, verifica-se haver certa oscilação nas respostas entre o sujeito da língua/da linguagem tomadas em seu aspecto formal e o sujeito da língua/da linguagem tomadas em seu aspecto de atividade. Isso não se deve às diferenças de pressupostos dos entrevistados, mas ao reconhecimento da própria complexidade do objeto da lingüística, um sistema ciberneticamente aberto, ou seja, sujeito a influências de outros sistemas e que igualmente influencia esses sistemas com que interage. É contudo motivo de satisfação ver que as reflexões desses profissionais caminham na direção de um monismo conceitual e prático na linha de Espinoza e de Vygotsky, dado que reconhecem, tomadas em conjunto, a imbricação entre os aspectos psico-fisiológicos e sócio-históricos do fenômeno da linguagem verbal. Também nesse aspecto as entrevistas mostram um avanço na reflexão lingüística.

Outro importante aspecto é a refutação do utilitarismo mercadológico como critério de determinação da validade e da importância dos estudos do campo; vê-se aí uma grande maturidade, pois essa recusa em momento algum envolve uma separação entre estudos puros e estudos aplicados, mas a defesa do empreendimento lingüístico como valioso por contribuir para a compreensão dos seres humanos, a par da plena aceitação de que estudos voltados para fins mais práticos têm o mesmo valor que os estudos que não estão especificamente voltados para isso. Por outro lado, há a defesa da ética da pesquisa como valor fundamental; os entrevistados revelam plena consciência de sua responsabilidade social como antes de tudo cidadãos, recusando a imagem do cientista alienado que nada conhece além de experimentos, axiomas, postulados e coisas do gênero.

A responsabilidade social dos cientistas é hoje um tema inescapável, dado que os estudos lingüísticos, afastando-se de tendências normativizantes, sem no entanto desprezar o normativo como realidade social e histórica a ser levada na devida conta e que deve ser acessível a todos, por razões de promoção da inclusão social e de formação de uma identidade "cidadã", podem contribuir tanto para perpetuar discrimina- 
ções como para combatê-las. O lingüista não pode se furtar, por exemplo, a tomar posição no debate sobre política lingüística, que continua na ordem do dia, do mesmo modo como não pode permitir que seu trabalho sirva a relativismos falsamente libertadores, tão nefastos quanto os absolutismos que pretendem combater.

A pergunta sobre a pós-modernidade revela um aspecto sobremodo interessante: prevalece a idéia da pós-modernidade como marcada pela interdisciplinaridade, e em alguns casos transdiciplinaridade, pela imprecisão dos limites das disciplinas, pela possibilidade de ir além em várias direções conexas, o que reforça a idéia, presente nas respostas a outras questões, de que a concepção de lingüística que marca a atividade desses pesquisadores se ampliou e se aprimorou, incorporando como legítimos novos objetos e novas abordagens e deixando de lado as concepções defensivas de cientificidade da lingüística do período de luta pela consolidação como campo de estudos legítimo, sem no entanto desprezar as bases duramente assentadas de lá para cá. Da adequada consideração dos aspectos sistemáticos e assistemáticos do fenômeno da linguagem, bem como do que há de fluido no sistemático e de formalizável no assistemático haverá de nascer o conhecimento complexo (Morin) desse ingrediente constitutivo da vida humana - eis o que se pode depreender das considerações dos entrevistados com respeito às relações entre lingüística e pósmodernidade, como quer que entendamos esta última.

Merece além disso destaque o fato de as reflexões apresentadas serem legitimamente brasileiras, ou melhor, em reconhecimento aos brasileiros-estrangeiros presentes no livro, legitimamente situadas no contexto do Brasil: sem deixar de levar em conta, incorporar e ressignificar antropofagicamente tendências de estudo e vários outros aspectos originários de outras plagas, os pesquisadores entrevistados mostram, sejam eles da geração fundadora ou da geração lutadora, um pensamento alicerçado na realidade em que vivem, em sua prática diária de estudiosos, e voltado para essa realidade. Ou seja, revelam estar atentos ao conhecimento lingüístico que circula no mundo e às especificidades do país em que vivem. Eis uma versão positiva da injunção "pense globalmente, aja localmente", cada vez mais na ordem do dia. Que prova maior de maturidade se poderia esperar?

O tema dos desafios da lingüística traz um espectro tão grande de possibilidades e necessidades que constitui por si só uma proposta de mudança de paradigma! Porque envolve desde o aprofundamento do conhecimento do aspecto cognitivo, e mesmo biológico, da linguagem como a proposta de uma lingüística voltada para a promoção da paz, passando pelo desenvolvimento de propostas voltadas para as mais diversas áreas, 
teóricas e práticas, como a de um inventário de modalidades de discurso. Há a ênfase na necessidade de estudo mais aprofundado da "produção" da linguagem, sem desprezo do "produto" lingüístico, o apelo para que se levem em conta as descontinuidades ligadas à linguagem verbal, para que se reconheça que o próprio ser da linguagem, é antes da ordem do fluido do que do organizado, como é adequado a um fenômeno distintivo da espécie humana. $\mathrm{Ou}$, nas palavras científico-poéticas do maître-à-penser Ataliba de Castilho: "Quando o estruturalismo se implantou aqui no Brasil, se dizia que o coração da língua era ocupado por sua estrutura e que pendentes dela havia aí umas franjas pequeninas, um conjunto não estruturado, porque estavam em processo de cristalização. Hoje é o contrário o que a gente acha. As franjazinhas é que são as estruturas prontas, o grande miolo está tomado por processos muito complexos, mas que estão sendo atacados nas pesquisas contemporâneas" (p.61). Essa compreensão, se revela ser sobremodo complexa a tarefa do lingüista, abre igualmente um vasto campo de estudos que só pode contribuir para uma melhoria do auto-conhecimento, social e historicamente situado, da constituição de uma identidade brasileira - sem falsos nacionalismos.

Faz-se presente ainda a proposta da exploração das relações da lingüística com a inteligência artificial, com modelos computacionais, bem como a de aprofundar, por meio do estudo dos discursos e dos mecanismos lingüísticos nele presentes, o conhecimento da linguagem, do homem, da sociedade, da cultura e do Brasil em particular (p.157), merecendo menção a proposta de aprofundamento das contribuições da lingüística a vários campos vinculados com a educação, inclusive de pessoas afetadas por problemas físicos que prejudicam o exercício da linguagem verbal. No momento em que a

A reflexão a que nos levam, e o conhecimento que nos trazem, as contribuições de Conversas com lingüistas não somente revelam o amadurecimento cada vez maior das concepções, dos estudos, das aplicações da ciência da linguagem no Brasil, bem como do pensamento de seus praticantes, como permitem ao leitor, seja leigo ou especializado, ter uma excelente visão de conjunto da lingüística, da língua, da linguagem e de temas conexos. Um livro indispensável! 